\title{
Erratum to: Listen protect connect for traumatized schoolchildren: a pilot study of psychological first aid
}

Marizen Ramirez ${ }^{1,2^{*}}$, Karisa Harland ${ }^{2}$, Maisha Frederick², Rhoda Shepherd ${ }^{3}$, Marleen Wong ${ }^{4}$ and Joseph E Cavanaugh ${ }^{2,5}$

\section{Erratum}

Due to an error in the publication process, this article (Ramirez et al. 2013) was published with an incorrect figure for Figure three (Figure 1 here).

BioMed Central have now corrected this error and Figure three (Figure 1 here) can be found in this article. We apologise to the authors and the readers for any inconvenience caused.

\section{Author details}

'Department of Occupational and Environmental Health, University of lowa, 105 S. River St. \#318, lowa City, IA 52242, USA. ${ }^{2}$ Injury Prevention Research Center, University of lowa, lowa City, IA, USA. ${ }^{3}$ Cedar Rapids Community School District, Cedar Rapids, IA, USA. ${ }^{4}$ School of Social Work, University of Southern California, Los Angeles, CA, USA. ${ }^{5}$ Department of Biostatistics,

University of lowa, lowa City, IA, USA.
Received: 2 October 2014 Accepted: 2 October 2014

Published online: 25 October 2014

\section{Reference}

Ramirez, M, Harland, K, Frederick, M, Shepherd, R, Wong, M, \& Cavanaugh, JE. (2013). Listen protect connect for traumatized schoolchildren: a pilot study of psychological first aid. BMC Psychology, 1, 26.

doi:10.1186/s40359-014-0045-0

Cite this article as: Ramirez et al: Erratum to: Listen protect connect for traumatized schoolchildren: a pilot study of psychological first aid. BMC Psychology 2014 2:45.

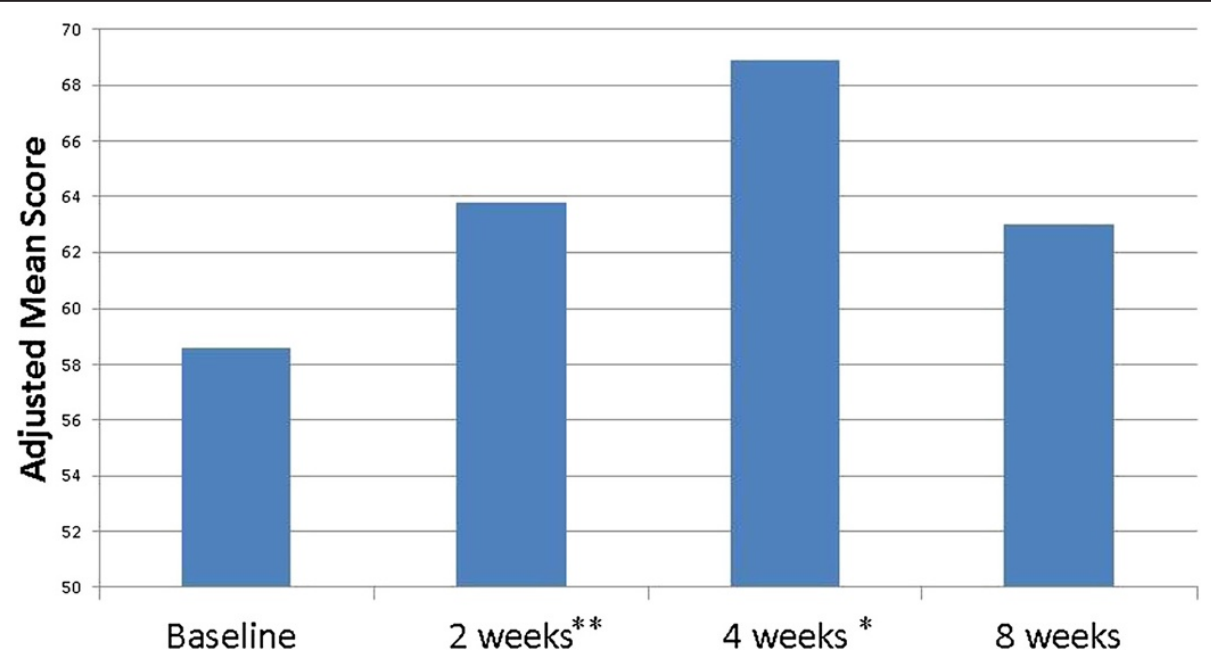

Figure 1 Mean school connectedness, lowa PFA Pilot, $\mathbf{N}=71$ measurements ${ }^{1} .{ }^{1}$ Mixed effects model controls for student race, grade and sex, flood versus other trauma and correlation within a student. 71 measurements completed on 20 students. ${ }^{*} p<0.05$, ${ }^{* *} p<0.10$ compared to baseline.

* Correspondence: marizen-ramirez@uiowa.edu

'Department of Occupational and Environmental Health, University of lowa 105 S. River St. \#318, lowa City, IA 52242, USA

${ }^{2}$ Injury Prevention Research Center, University of lowa, lowa City, IA, USA 